$05 ; 13$

\title{
Изменение морфологии, структуры и микротвердости образцов циркониевого сплава в результате воздействия лазерными импульсами
}

\author{
(С) В.И. Проскуряков, И.В. Родионов, В.А. Кошуро, Л.Е. Куц, И.В. Перинская \\ Саратовский государственный технический университет им. Гагарина Ю.А., Саратов, Россия \\ E-mail: prosku.94@mail.ru
}

Поступило в Редакцию 10 сентября 2019 г.

В окончательной редакции 1 октября 2019г.

Принято к публикации 1 октября 2019 г.

\begin{abstract}
Представлены результаты экспериментальных исследований по модифицированию поверхностного слоя циркониевого сплава марки Э-110 при воздействии импульсного лазерного излучения. Установлено, что в результате лазерной обработки происходит изменение морфологии поверхностного слоя с образованием наночастиц размером до $50 \mathrm{~nm}$. Рельеф обрабатываемой поверхности становится структурно-гетерогенным, содержащим фазы циркония и моноклинного диоксида $\mathrm{ZrO}_{2}$. Выявлено, что в результате воздействия лазерных импульсов происходит существенное повышение микротвердости поверхности циркониевых образцов до $27.1 \pm 0.1 \mathrm{GPa}$.
\end{abstract}

Ключевые слова: цирконий, лазерное упрочнение, наноструктурирование поверхности, микротвердость.

DOI: 10.21883/PJTF.2020.01.48856.18029

Благодаря своим повышенным прочностным параметрам, коррозионной стойкости к воздействию различных агрессивных сред и низкому сечению захвата тепловых нейтронов цирконий и сплавы на его основе нашли широкое применение в машиностроительной отрасли, атомной промышленности, приборостроении, медицинской технике и т. д. Из циркония изготавливают медицинские имплантаты, хирургический инструмент, оболочки твэлов, охладительные трубки ядерных реакторов, теплообменники, детали горячей запорной арматуры $[1,2]$. Однако известно, что в процессе эксплуатации при повышенных температурах (около $400^{\circ} \mathrm{C}$ ) под воздействием перегретой воды или перегретого водяного пара, а также при взаимодействии с углекислым газом происходит окисление поверхности металла, что приводит к постепенному разрушению циркониевых изделий $[3,4]$.

В настоящее время известен широкий спектр технологий модификации поверхностного слоя, способных повысить эксплуатационные характеристики металлических изделий и защитить их от преждевременного износа. К таким технологиям можно отнести электрохимические, газотермические и электрофизические методы формирования защитных барьерных покрытий, поверхностно-деформационное упрочнение, термическую и лазерную обработку [4-8].

К наиболее перспективным и экономически целесообразным технологиям повышения эксплуатационных характеристик и защиты от преждевременного износа металлов и сплавов в условиях воздействия агрессивных сред можно отнести способы лазерной обработки поверхности. Такие способы модификации поверхностного слоя являются достаточно эффективными. Лазерное микро- и наноструктурирование поверхности отличается относительной простотой реализации и дешевизной, контролируемостью и воспроизводимостью процесса. Также наиболее значимой отличительной особенностью метода лазерной модификации является возможность локальной обработки поверхности, что позволяет значительно минимизировать время, количество расходуемого материала, а также затрачиваемые энергоресурсы $[9,10]$.

При воздействии лазерного импульса на обрабатываемую поверхность происходит изменение структурного состояния, а также физико-механических свойств за счет высокоскоростного нагрева и последующего быстрого охлаждения обрабатываемого участка и происходящих при этом процессов рекристаллизации. В результате импульсной лазерной обработки ряда металлов и сплавов на модифицируемой поверхности происходит формирование структур нанометрового масштаба, что приводит к улучшению как физических, так и механических свойств обрабатываемого материала, улучшаются коррозионная стойкость и сверхпластичность. Известно, что микротвердость наноструктурированной поверхности ряда материалов в 2-7 раз выше, чем твердость крупнозернистых аналогов. В зависимости от рабочей атмосферы происходит изменение элементно-фазового состава. Однако особенности процесса лазерного упрочнения циркония недостаточно полно изучены $[11,12]$.

Поэтому цель настоящей работы заключается в исследовании изменений характеристик поверхности циркония в результате лазерной обработки и установлении влияния режимов импульсного воздействия на микротвердость модифицируемого слоя.

В качестве экспериментальных образцов использовались пластины размером $10 \times 10 \times 3 \mathrm{~mm}$ из циркониевого сплава марки Э-110. Модифицируемая поверхность 


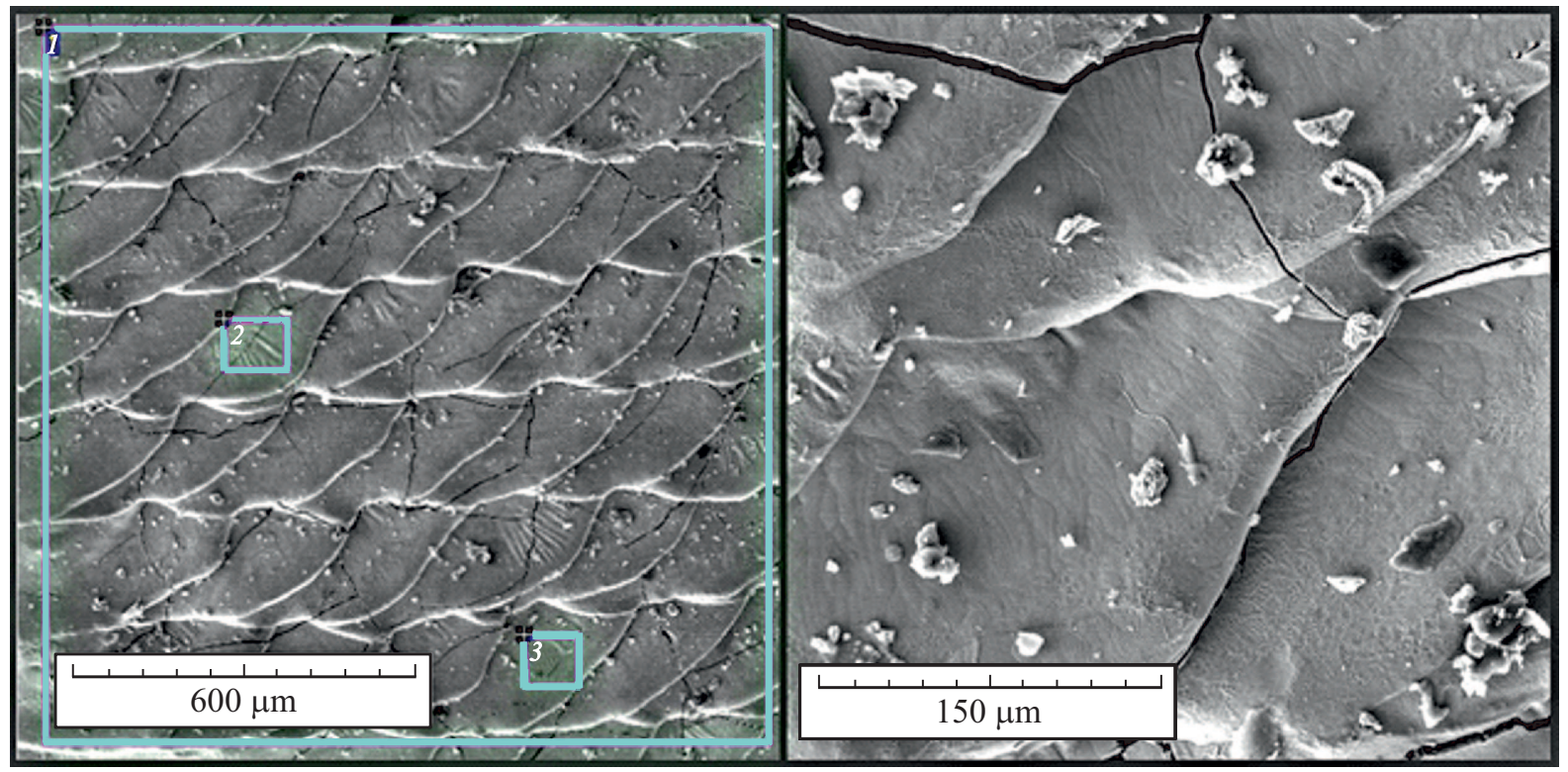

Рис. 1. Морфология поверхности циркония после лазерной обработки. $1-3$ - обозначения спектров областей, по которым проводился ЭДРФА.

Таблица 1. Элементный и фазовый состав поверхности циркония после лазерной обработки

Элементный состав модифицированной поверхности циркония, at.\%

\begin{tabular}{c|c|c|c|c|c}
\hline Спектр & $\mathrm{O}$ & $\mathrm{Fe}$ & $\mathrm{N}$ & $\mathrm{Zr}$ & $\mathrm{W}$ \\
\hline 1 & 13.71 & 0.97 & & 85.32 & \\
2 & 11.12 & 0.47 & 2.55 & 85.03 & 0.83 \\
3 & 12.02 & 0.30 & & 86.92 & 0.76 \\
\hline
\end{tabular}

Фазовый состав модифицированной

поверхности циркония

\begin{tabular}{c|c|c|c}
\hline \multicolumn{2}{|c|}{$\mathrm{Zr}$} & \multicolumn{2}{c}{$\mathrm{ZrO}_{2}$ (моноклинный) } \\
\hline$d, \AA$ & $J$, rel. un. & $d, \AA$ & $J$, rel. un. \\
\hline 2.79 & 244 & 5.05 & 59.2 \\
2.57 & 254 & 3.63 & 119 \\
2.45 & 650 & 3.15 & 650 \\
1.89 & 143 & 2.83 & 678 \\
1.61 & 161 & 2.60 & 135 \\
1.46 & 165 & 2.33 & 51.7 \\
1.36 & 170 & 2.20 & 136 \\
1.35 & 121 & 1.84 & 180 \\
& & 1.81 & 221 \\
& & 1.68 & 111 \\
& & 1.64 & 91 \\
& & 1.47 & 103
\end{tabular}

подвергалась предварительной шлифовке влагостойкой наждачной бумагой зернистостью P600 (ISO-6344) и последующей очистке от технологических загрязнений методом ультразвуковой (УЗ) обработки с использо- ванием УЗ-ванны „Кристалл-2.5“ в водных растворах поверхностно-активных веществ и этилового спирта в течение $20 \mathrm{~min}$.

Лазерное воздействие осуществлялось с использованием автоматизированной установки для термофизической когерентной модификации поверхности LRS-50A при напряжении импульса $U=350,375,400,425,450$ и $475 \mathrm{~V}$. Длительность $\tau$ импульсного воздействия составляла $0.7,0.85$ и $1 \mathrm{~ms}$. Луч фокусировался в пятно диаметром $1 \mathrm{~mm}$. Сканирование поверхности осуществлялось при частоте следования импульсов $15 \mathrm{~Hz}$ и коэффициенте перекрытия 0.1 .

Элементный состав и морфология модифицируемого слоя исследовались методами энергодисперсионного рентгенофлуоресцентного анализа (ЭДРФА) (погрешность концентраций \pm 0.5 at.\%) и растровой электронной микроскопии (РЭМ) на электронном микроскопе „MIRA II LMU“ с детектором „INCA PentaFETx3“.

Фазовый состав устанавливался методом рентгенофазового анализа с помощью дифрактометра ДРОН-4, снабженного рентгеновской трубкой с медным анодом, в $\mathrm{Cu} K_{\alpha}$-излучении при сканировании брэгговского угла со скоростью $2 \mathrm{deg} / \mathrm{min}$. Идентификация фаз на получаемых дифрактограммах производилась с помощью компьютерной программы, содержащей данные картотек ASTM и JCPOS.

Микротвердость измерялась с использованием твердомера ПМТ-3М с индентором Виккерса при нагрузке на индентор $1.961 \mathrm{~N}$ (ISO 6507-1:2005). Статистическая обработка результатов исследования проводилась с использованием программы DataFit 9.

Исследования микроструктуры поверхности с помощью РЭМ показали, что в результате лазерной обра- 
Таблица 2. Среднестатистические значения микротвердости поверхности циркониевых образцов, модифицированных лазерным излучением

\begin{tabular}{c|c|c}
\hline$\tau, \mathrm{ms}$ & $U, \mathrm{~V}$ & $H, \mathrm{GPa}$ \\
\hline 0.7 & 350 & $24.4 \pm 0.1$ \\
& 375 & $19.9 \pm 0.1$ \\
& 400 & $27.1 \pm 0.1$ \\
& 425 & $26.8 \pm 0.1$ \\
& 450 & $22.7 \pm 0.1$ \\
& 475 & $21.7 \pm 0.1$ \\
& 350 & $13.6 \pm 0.1$ \\
& 375 & $17.6 \pm 0.1$ \\
& 400 & $16.9 \pm 0.1$ \\
& 425 & $18.6 \pm 0.1$ \\
& 450 & $26.5 \pm 0.1$ \\
& 475 & $26.1 \pm 0.1$ \\
& 350 & $17.6 \pm 0.1$ \\
& 375 & $18.4 \pm 0.1$ \\
& 400 & $19.7 \pm 0.1$ \\
& 425 & $25.5 \pm 0.1$ \\
& 450 & $33.8 \pm 0.1$ \\
& 475 & $23.2 \pm 0.1$
\end{tabular}

ботки циркония происходит формирование равномерно распределенного гетерогенного поверхностного слоя. Поверхность характеризуется повторяющимся рельефом с четко различимыми границами кратеров, образовавшихся при обработке поверхности лазерным излучением. В ходе обработки было обнаружено образование микротрещин, которые более четко визуализируются при напряжении лампы накачки лазерной установки свыше $400 \mathrm{~V}$ (рис. 1).

Установлены изменения химического состава модифицированной поверхности в результате импульсного воздействия. Согласно проведенным спектральным исследованиям, основными элементами сформированного слоя являются кислород (13.71-12.02 at.\%) и цирконий (85.32-86.92 at.\%) (табл. 1). Кроме того, обнаружено присутствие следового количества азота $(2.55$ at.\%), железа в диапазоне $(0.97-0.30$ at.\%) и вольфрама $(0.83-0.76$ at.\%).

Наличие высокого содержания кислорода в зоне импульсного воздействия показывает, что в процессе обработки происходит поглощение кислорода локально активированными участками поверхности с их последующим окислением.

Согласно результатам проведенного рентгенофазового анализа, было установлено, что лазерная обработка в воздушной среде приводит к образованию на поверхности циркония оксидной структуры. Результаты обработки рентгеновской дифрактограммы показали, что значения межплоскостного расстояния $d$ при различной величине интенсивности дифракционных пиков $J$ соответствовали присутствию на поверхности наибольшего количества фаз циркония и его диоксида $\mathrm{ZrO}_{2}$ с моноклинной кристаллической решеткой (табл. 1).

Результаты измерения микротвердости $(H)$ показали, что в процессе лазерного импульсного воздействия микротвердость поверхности циркониевых образцов значительно увеличивается (табл. 2). Максимальное значение $H=27.1 \pm 0.1 \mathrm{GPa}$ было получено при напряжении $400 \mathrm{~V}$ и длительности импульсного воздействия $0.7 \mathrm{~ms}$. Следует отметить, что значение микротвердости поверхности исходного образца циркония составляло $2.6 \pm 0.1 \mathrm{GPa}$.

По данным, полученным с использованием компьютерной программы статистической обработки результатов DataFit 9, была построена эмпирическая модель зависимости микротвердости поверхности циркония $H$ от режимов лазерного модифицирования (рис. 2).

Построенная эмпирическая модель описывается регрессионным уравнением

$$
\begin{aligned}
& H=(-184.282)+1.0037 x_{1}+(-26.2656) / x_{2} \\
& +(-1.0128) x_{1}^{2}+33.2538 / x_{2}^{2}+(-0.126) x_{1} / x_{2},
\end{aligned}
$$

где $x_{1}$ - напряжение $(U, \mathrm{~V}), x_{2}$ - длительность импульсного воздействия $(\tau, \mathrm{ms})$.

Из данной модели следует, что значительное упрочнение поверхностного слоя циркония происходит при напряжении от 380 до $420 \mathrm{~V}$ и длительности импульсов 0.9-1.0 ms, а минимальное значение микротвердость поверхности принимает при напряжении $340 \mathrm{~V}$ и длительности $0.85-1.00 \mathrm{~ms}$.

Методом РЭМ установлено образование наночастиц на обрабатываемой поверхности, размер которых в среднем составляет менее $50 \mathrm{~nm}$ (рис. 3). Ввиду того что при уменьшении размера зерен до критических значений кристаллические решетки становятся бездислокационными, можно предположить, что повышение микротвердости поверхностного слоя циркония связано с образованием наноструктур.

Так, данные РЭМ и рентгенофазового анализа показали, что на обрабатываемой поверхности происходит формирование наноструктур, состоящих в основном из диоксида $\mathrm{ZrO}_{2}$ с моноклинной решеткой. При этом

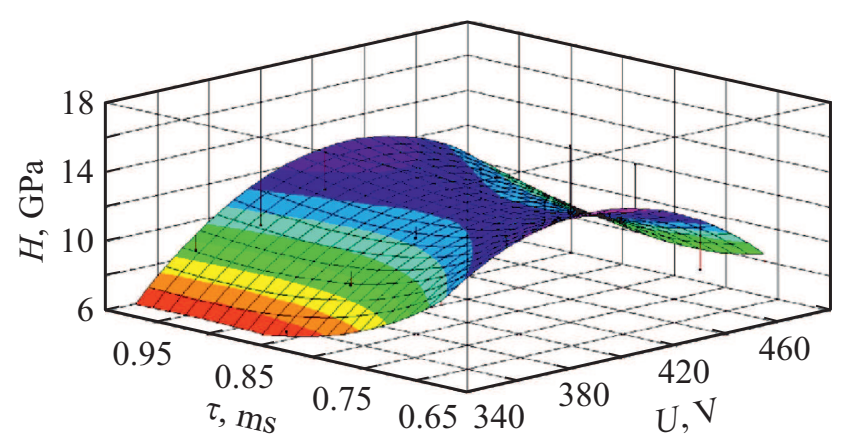

Рис. 2. Зависимость микротвердости поверхности циркония от режимов лазерного модифицирования. 


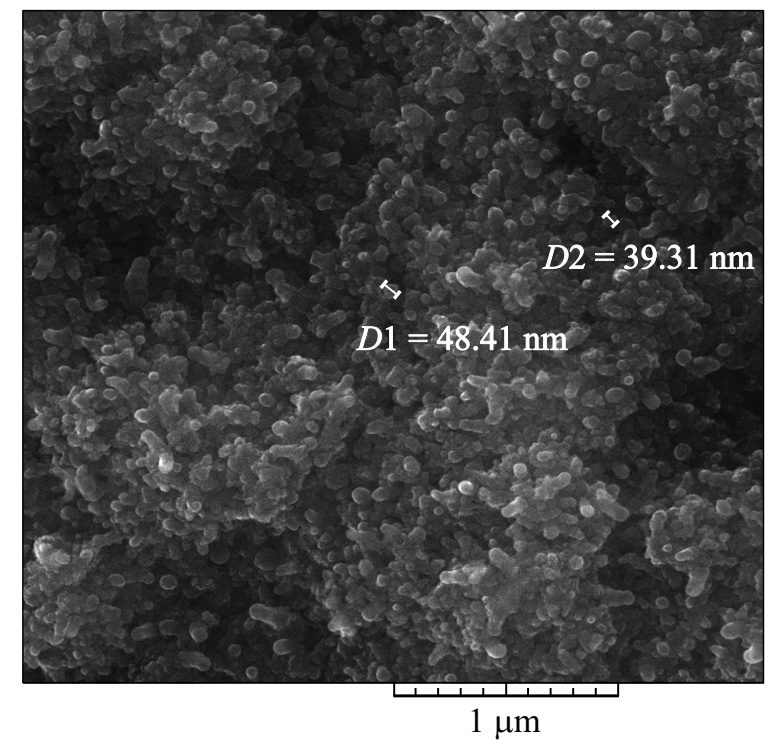

Рис. 3. Микро- и наноразмерная структура поверхности циркония, получаемая в результате лазерной обработки при длительности импульсного воздействия $\tau=1 \mathrm{~ms}$ и напряжении импульса $U=425 \mathrm{~V}$.

такая модифицированная поверхность характеризуется высокими показателями микротвердости, зависящими в большей степени от напряжения импульсов. Это позволяет рекомендовать лазерную импульсную модификацию циркония при длительности импульсного воздействия $\tau=0.7 \mathrm{~ms}$ и напряжении импульса $U=400 \mathrm{~V}$ для получения механически прочных функциональных поверхностей.

\section{Финансирование работы}

Исследования выполнены при финансовой поддержке Минобрнауки РФ в рамках государственного задания образовательным организациям высшего образования, подведомственным Минобрнауки РФ (проект № 11.1943.2017/4.6).

\section{Конфликт интересов}

Авторы заявляют, что у них нет конфликта интересов.

\section{Список литературы}

[1] Пилипенко Н.Н. // Вісник Харківського університету. 2009. T. 2. № 42. C. 44-50.

[2] Селезнева Л.В., Бушмин Б.В., Дубровский Ю.В., Хазов И.А., Денисов Е.А., Курдюмов А.А. // Вопр. атомной науки и техники. 2008. № 2. С. 108-111.

[3] Тихов С.В., Горшков О.Н., Павлов Д.А., Антонов И.Н., Бобров А.И., Касаткин А.П., Шенина М.Е. // Письма в ЖТФ. 2014. Т. 40. В. 9. С. 9-16.

[4] He X.M., Shu L., Li H.B., Li H.D., Lee S.T. // J. Vac. Sci. Technol. 1998. V. 16. N 4. P. 2337-2344.
[5] Чернов И.П., Иванова С.В., Кренинг М.Х., Коваль Н.Н., Ларионов В.В., Лидер А.М., Черданцев Ю.П. // ЖТФ. 2012. T. 82. B. 3. C. 81-89.

[6] Борисов А.М., Востриков В.Г., Романовский Е.А., Ткаченко Н.В., Виноградов А.В., Крит Б.Л., Савушкина С.В., Полянский М.Н. // Поверхность. Рентгеновские, синхротронные и нейтронные исследования. 2013. № 4. С. 76-80.

[7] Проскуряков В.И., Родионов И.В., Кошуро В.А., Егоров И.С. // News of Science and Education. 2017. Т. 7. № 3. C. 067-074.

[8] Koshuro V., Fomina M., Voyko A., Zakharevich A., Skaptsov A., Rodionov I. // 4rd Int. School and Conf. on optoelectronics, photonics, engineering and nanostructures „Saint Petersburg OPEN 2017“،. St. Petersburg, Russia, 2017. P. 64-65.

[9] Chai L. Chen K., Zhi Y., Murty K.L., Chen L.Y., Yang Z. // J. Alloys Compd. 2018. V. 748. P. 163-170.

[10] Федоров В.А., Шлыкова А.А., Яковлев А.В. // Вестн. Тамбов. ун-та. 2017. Т. 22. № 5-2. С. 1100-1108.

[11] Zhu Y., Fu J., Zheng C., Ji Z. // Opt. Laser Technol. 2016. V. 83. P. 21-27.

[12] Koshuro V., Fomina M., Voyko A., Rodionov I., Zakharevich A., Skaptsov A., Fomin A. // Comp. Struct. 2018. V. 202. P. $210-215$. 